\title{
Mechanical preconditioning enables electrophysiologic coupling of skeletal myoblast cells to myocardium
}

\author{
Klaus Neef, PhD, ${ }^{\text {a,b }}$ Yeong-Hoon Choi, MD, ${ }^{\text {a,b }}$ Sureshkumar Perumal Srinivasan, MS, ${ }^{\text {a,b }}$ \\ Philipp Treskes, MS, ${ }^{\mathrm{a}, \mathrm{b}}$ Douglas B. Cowan, PhD, ${ }^{\mathrm{c}}$ Christof Stamm, MD, ${ }^{\mathrm{d}}$ Martin Rubach, MS, \\ Roland Adelmann, MD, ${ }^{\mathrm{e}}$ Thorsten Wittwer, MD, ${ }^{\mathrm{a}, \mathrm{b}}$ and Thorsten Wahlers, MD ${ }^{\mathrm{a}, \mathrm{b}}$
}

\begin{abstract}
Objective: The effect of mechanical preconditioning on skeletal myoblasts in engineered tissue constructs was investigated to resolve issues associated with conduction block between skeletal myoblast cells and cardiomyocytes.
\end{abstract}

\begin{abstract}
Methods: Murine skeletal myoblasts were used to generate engineered tissue constructs with or without application of mechanical strain. After in vitro myotube formation, engineered tissue constructs were co-cultured for 6 days with viable embryonic heart slices. With the use of sharp electrodes, electrical coupling between engineered tissue constructs and embryonic heart slices was assessed in the presence or absence of pharmacologic agents.
\end{abstract}

\begin{abstract}
Results: The isolation and expansion procedure for skeletal myoblasts resulted in high yields of homogeneously desmin-positive $(97.1 \% \pm 0.1 \%)$ cells. Mechanical strain was exerted on myotubes within engineered tissue constructs during gelation of the matrix, generating preconditioned engineered tissue constructs. Electrical coupling between preconditioned engineered tissue constructs and embryonic heart slices was observed; however, no coupling was apparent when engineered tissue constructs were not subjected to mechanical strain. Coupling of cells from engineered tissue constructs to cells in embryonic heart slices showed slower conduction velocities than myocardial cells with the embryonic heart slices (preconditioned engineered tissue constructs vs embryonic heart slices: $0.04 \pm 0.02 \mathrm{~ms}$ vs $0.10 \pm 0.05 \mathrm{~ms}, P=.011$ ), lower maximum stimulation frequencies (preconditioned engineered tissue constructs vs embryonic heart slices: $4.82 \pm 1.42 \mathrm{~Hz}$ vs $10.58 \pm 1.56 \mathrm{~Hz} ; P=.0009$ ), and higher sensitivities to the gap junction inhibitor (preconditioned engineered tissue constructs vs embryonic heart slices: $0.22 \pm 0.07 \mathrm{mmol} / \mathrm{L}$ vs $0.93 \pm 0.15 \mathrm{mmol} / \mathrm{L} ; P=.0004)$.
\end{abstract}

Conclusions: We have generated skeletal myoblast-based transplantable grafts that electrically couple to myocardium. (J Thorac Cardiovasc Surg 2012;144:1176-84)

Supplemental material is available online.

Skeletal myoblast cells (SMBs) have been investigated for cardiac cell therapy of congestive heart failure since the

From the Department of Cardiac and Thoracic Surgery, ${ }^{\mathrm{a}}$ Heart Center of the University, University of Cologne, Cologne, Germany; Center for Molecular Medicine, ${ }^{b}$ University of Cologne, Cologne, Germany; Department of Pediatric Cardiology, ${ }^{c}$ Heart Center of the University, University of Cologne, Cologne, Germany; Department of Anesthesiology, ${ }^{\mathrm{d}}$ Perioperative and Pain Medicine, Children's Hospital Boston and Harvard Medical School, Boston, Mass; and Berlin-Brandenburg Center for Regenerative Therapies, ${ }^{\mathrm{e}}$ Berlin, Germany.

Disclosures: Authors have nothing to disclose with regard to commercial support.

Read at the 92nd Annual Meeting of The American Association for Thoracic Surgery, San Francisco, California, April 28-May 2, 2012.

K.N., Y.-H.C., and S.P.S. contributed equally to this work.

Received for publication April 29, 2012; revisions received June 10, 2012; accepted for publication July 25, 2012; available ahead of print Sept 13, 2012.

Address for reprints: Yeong-Hoon Choi, MD, Department of Cardiac and Thoracic Surgery, Heart Center of the University, Center of Molecular Medicine Cologne, University of Cologne, Kerpener St 62, 50924 Cologne, Germany (E-mail: yh. choi@uk-koeln.de).

0022-5223/\$36.00

Copyright (c) 2012 by The American Association for Thoracic Surgery

http://dx.doi.org/10.1016/j.jtcvs.2012.07.036 1990s. Despite limited information about safety and efficacy, Hagege and colleagues ${ }^{1}$ applied SMBs in a clinical trial. As shown in the Myoblast Autologous Grafting in Ischemic Cardiomyopathy trial, the inability of SMBs to integrate functionally and electrically to the host myocardium resulted in adverse ventricular arrhythmias. ${ }^{2}$ At the same time, it was demonstrated that unmodified transplanted SMBs neither integrate into the host myocardium nor transdifferentiate into cardiomyocytes. ${ }^{3}$

On the other hand, it has been shown that SMBs, which have been preconditioned before transplantation, were able to integrate into the host myocardium. ${ }^{4-11}$ The preconditioning regimens included virally mediated expression of connexin43 ( $\mathrm{Cx} 43$ ), in vitro co-culturing of SMBs with cardiomyocytes, and chemical induction of Cx43 expression. Because autologous cardiomyocytes are difficult to obtain and there are safety issues associated with transgenic approaches, these methods may not be clinically relevant.

Other cell types that have been applied for cardiac cell therapy approaches include mesenchymal stem cells, endothelial progenitor cells, and cardiac cells derived from pluripotent stem cells. Although all of these cells have been 


$$
\begin{aligned}
& \text { Abbreviations and Acronyms } \\
& \begin{aligned}
\text { AP } & =\text { action potential } \\
\text { Cx43 } & =\text { connexin } 43 \\
\text { DMEM } & =\text { Dulbecco's Modified Eagle Medium } \\
\text { EGFP } & =\text { enhanced green fluorescent protein } \\
\text { EHS } & =\text { embryonic heart slice } \\
\text { ETC } & =\text { engineered tissue construct } \\
\text { FBS } & =\text { fetal bovine serum } \\
\text { K-ETC } & =\text { killed engineered tissue construct } \\
\text { NP- } & =\text { nonpreconditioned engineered tissue } \\
\text { ETC } & \text { construct } \\
\text { P-ETC } & =\text { preconditioned engineered tissue } \\
& \text { construct } \\
\text { SMB } & =\text { skeletal myoblast cell }
\end{aligned}
\end{aligned}
$$

shown to exert some myocardial effects, ${ }^{12}$ the underlying mechanisms remain unknown. Furthermore, we have shown that the quality of autologous progenitor cells (ie, mesenchymal stem cells) is dependent on patient-specific factors. ${ }^{13}$ Because of ethical and safety reasons, so-called embryonic stem cells and induced pluripotent stem cells, respectively, are not considered for clinical application at this time.

Our group ${ }^{14}$ previously demonstrated a method to precondition rat SMBs in a manner that could be clinically applicable. By seeding the cells into a 3-dimensional hydrogel construct and subjecting them to tensile strain, the expression levels of proteins essential for functional and electrical coupling were significantly increased. After transplantation, the skeletal cells were able to establish an accessory conduction pathway as a potential treatment for atrioventricular conduction block.

We sought to address known electrophysiologic issues of SMB transplantation for cardiac therapy ${ }^{2}$ by investigating the electrical coupling properties of SMBs, embedded in mechanically preconditioned engineered tissue constructs (ETCs), to myocardium in an ex vivo transplantation model.

\section{MATERIALS AND METHODS}

\section{Isolation and Cell Culture of Skeletal Myoblast Cells}

Animals received humane care in compliance with the Principles of Laboratory Animal Care, formulated by the National Society of Medical Research, and the Guide for the Care and Use of Laboratory Animals, prepared by the National Academy of Sciences and published by the National Institutes of Health (Publication No. 86-23, revised 1996). The Institutional Animal Care and Use Committee approved all experiments. All experiments were approved by the local institutional and governmental authorities.

SMBs were isolated from the limb muscle tissue of neonatal C57BL/6 mice as described previously. ${ }^{15}$ The tissue sample processing involved incubation in $0.2 \%$ type IV collagenase (Invitrogen, Karlsruhe, Germany), $2.4 \mathrm{IU} / \mathrm{mL}$ dispase (Invitrogen) and $3 \mathrm{mmol} / \mathrm{L} \mathrm{CaCl}_{2}$ (Sigma-Aldrich, Munich, Germany) in phosphate-buffered saline (Invitrogen). Isolation medium containing Ham's F10 medium (Invitrogen), 20\% fetal bovine serum (FBS, Invitrogen), and $2.5 \mathrm{ng} / \mathrm{mL}$ basic fibroblast growth factor (PeproTech, Hamburg, Germany) was applied for culturing the cells at a density of $1 \times 10^{5}$ cells $/ \mathrm{cm}^{2}$ on collagen-coated plates $\left(5 \mu \mathrm{g} / \mathrm{cm}^{2}\right.$ type I collagen, Invitrogen). Preplating procedures (ie, further culture of suspension cells, while adherent cells were discarded) were applied after 1,2, 18, and 48 hours of incubation. After a further incubation for 48 hours, the adherent cells were expanded in growth medium: 40\% Ham's F10 medium, $40 \%$ Dulbecco's Modified Eagle Medium (DMEM, Invitrogen), and 20\% FBS, $2.5 \mathrm{ng} / \mathrm{mL}$ basic fibroblast growth factor. Ten days after isolation at $80 \%$ confluence, differentiation of SMBs to myotubes was triggered by a change in culture conditions to differentiation medium: DMEM, $2 \%$ horse serum (PAA, Coelbe, Germany), which was changed daily for 14 days. All media were supplemented with penicillin/streptomycin (1:100) and fungizone (1:1000, both Invitrogen).

\section{Fabrication of Engineered Tissue Constructs}

ETC fabrication was based on a slightly modified method as previously published. ${ }^{15}$ The matrix scaffold for the ETC was prepared by mixing icecold isolation medium, type I collagen $(5 \mathrm{mg} / \mathrm{mL}$, Invitrogen), and 0.1 $\mathrm{mol} / \mathrm{L} \mathrm{NaOH}$ and Geltrex (Invitrogen) at a ratio of 3:3:1:1. SMBs were labeled with Vybrant DiI (Invitrogen) according to the manufacturer's instructions before using for ETCs. A defined number $\left(5 \times 10^{6}\right)$ of SMBs were resuspended in $200 \mu \mathrm{L}$ isolation medium and mixed with $500 \mu \mathrm{L}$ of the premixed matrix.

To fabricate preconditioned ETC (P-ETCs), the mixture was cast into molds composed of silicone tubing cut in half lengthwise with monofilament polyester mesh (0.331 opening; McMaster-Carr, Elmhurst, Ill) attached to each end with silicone adhesive (Rhodia, Cranbury, NJ). Constructs were warmed at $37^{\circ} \mathrm{C}$ to induce gelling and covered with myoblast culture media.

For the fabrication of nonpreconditioned ETCs (NP-ETCs), the suspension was poured directly on a cell culture dish (BD Biosciences, Heidelberg, Germany). The tissue constructs were first incubated at $37^{\circ} \mathrm{C}$ in isolation medium for 3 days followed by incubation in differentiation medium for 11 days. The complete timeline of the ETC fabrication protocol is as follows: skeletal muscle tissue preparation (day 0), preplating (days 0-3), cell culture expansion (days 3-10), ETC generation (day 10), ETC cell culture (days 10-13), ETC differentiation (days 13-24), and co-culture with embryonic heart slices (EHSs) (days 24-30).

\section{Preparation of Embryonic Ventricular Heart Slices}

Vital EHSs from day 18 C57BL/6 mice, expressing enhanced green fluorescent protein (EGFP) under control of the cardiac specific $\alpha$-actin promoter, were prepared as described previously. ${ }^{16,17}$ Briefly, the explanted hearts were prepared and embedded in 4\% low-melt agarose (Roth, Karlsruhe, Germany). These agarose blocks were subsequently sectioned into 300- $\mu \mathrm{m}$-thick transversal sections using a VT1000s microtome (Leica, Wetzlar, Germany) and stored in preoxygenized ice-cold Tyrode's solution (composition in mmol/L: $\mathrm{NaCl} 136, \mathrm{KCl} 5.4, \mathrm{NaH}_{2} \mathrm{PO}_{4} 0.33$, $\mathrm{MgCl}_{2}$ 1, D-glucose 10, 2,3-butanedione monoxime 30, and $\mathrm{N}-2$ hydroxyethylpiperazine-N'-2-ethanesulfonic acid 5; pH 7.4). After sectioning, $\mathrm{CaCl}_{2}$ (Sigma-Aldrich) was added to a final concentration of 0.9 $\mathrm{mmol} / \mathrm{L}$, and the tissue slices were incubated for 30 minutes at $4^{\circ} \mathrm{C}$. The EHSs were washed twice in phosphate-buffered saline and transferred to a 10-cm dish (BD Biosciences) containing ice-cold Iscove's modified Dulbecco's medium (Invitrogen) supplemented with 20\% FBS (Invitrogen). EHSs were incubated for 1 hour in a standard cell-culture incubator and then used for co-culture with ETCs.

\section{Engineered Tissue Construct Preparation and Co-Culture With Embryonic Heart Slices}

On day 11 of differentiation cell culture, the center regions (2-mm long) of P-ETCs were prepared using a sterile scalpel. The center parts of 

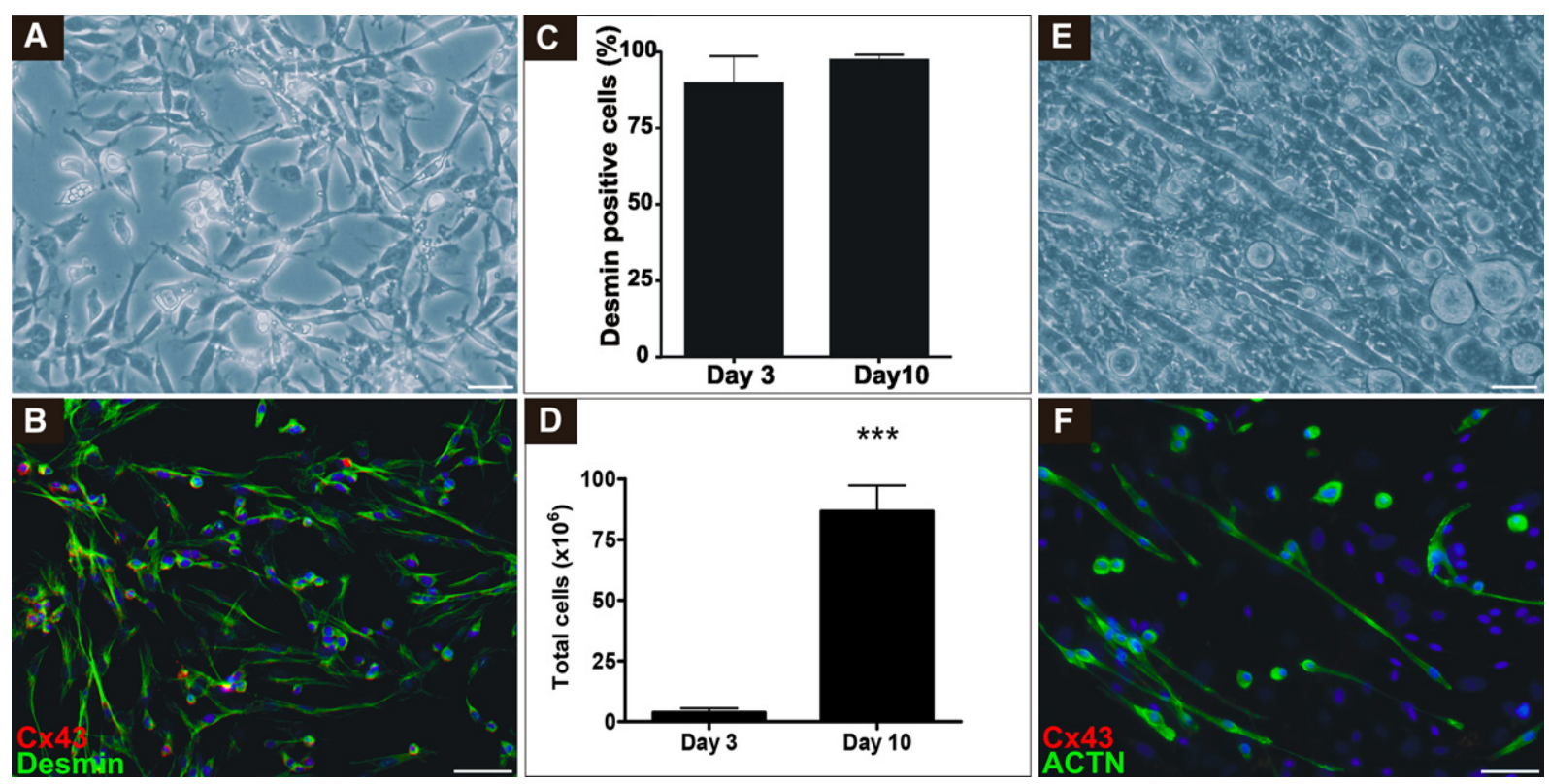

FIGURE 1. Isolation and characterization of SMBs. Bright field micrograph (A) and (B) immunocytochemical staining of SMBs after 7 days of cell culture: desmin (green), connexin43 (Cx43, red), and 4',6-diamidino-2-phenylindole-dihydrochloride (blue). C, Flow cytometric quantification of desmin expression in SMBs after preplating (day 3) and cell culture expansion (day 10). D, Quantification of total cell yield per 100 mg muscle tissue and fraction of desmin-positive cells after preplating (day 3 ) and cell culture expansion (day 10, $* * * P<.0001 ; \mathrm{n}=5$ ). Bright field micrograph (E) and (F) immunocytochemical staining of SMBs differentiated to myotubes: $\alpha$-actinin (ACTN, green), Cx43 (red), and 4',6-diamidino-2-phenylindole-dihydrochloride (blue) after 14 days of differentiation. Scale bars $=50 \mu \mathrm{m}$.

NP-ETCs were cut into similarly sized and shaped pieces. Control ETCs containing dead cells (killed [K]-ETCs) were prepared by immersing P-ETCs in distilled water for 24 hours.

EHSs and ETCs were transferred to a custom-made well chamber with a funnel-shaped cavity (funnel dish) to facilitate physical contact between EHSs and ETCs. After 6 days of incubation in differentiation medium, cocultures were used for immunohistochemistry and electrophysiologic assessment.

\section{Histology}

Tissue samples were snap-frozen in TissueTek (Sakura Finetek, Staufen, Germany) and cut into $8-\mu \mathrm{m}$ sections with a CM1950 cryotome (Leica).

For histochemistry, the sections were fixed with acetone and stained with Masson's trichrome (both Sigma-Aldrich) following the manufacturer's instructions.

For immunohistochemistry, the sections were fixed (4\% paraformaldehyde) and permeabilized ( $0.25 \%$ Triton X-100). Unconjugated primary antibodies used for immunocytochemistry included anti-desmin (GeneTex, Irvine, Calif), anti-connexin45 (Millipore, Schwalbach, Germany), antiCx43, anti-N-cadherin (both Abcam, Cambridge, UK), anti-sarcomeric$\alpha$-actinin (Sigma-Aldrich), anti-dystrophin, (Santa Cruz, Heidelberg, Germany), and anti-EGFP (Invitrogen). Primary antibodies were detected with species-specific AlexaFluor conjugated secondary antibodies. Nuclei were stained with 4',6-diamidino-2-phenylindole-dihydrochloride (both Invitrogen). Fluorescence microscopy was performed with an Eclipse Ti-U microscope using the NIS Elements BR 3.10 software package (Nikon, Düsseldorf, Germany).

\section{Electrophysiologic Analysis}

The funnel dish with the co-culture sample in $3 \mathrm{~mL}$ serum-free DMEM, oxygenated with $\mathrm{O}_{2} / \mathrm{CO}_{2}(95 \% / 5 \%)$, was placed on a custom-made heating plate $\left(37^{\circ} \mathrm{C}\right)$. Electrophysiologic measurements were performed with sharp electrodes (20-40 $\mathrm{M} \Omega$ when filled with $3 \mathrm{~mol} / \mathrm{L} \mathrm{KCl}$ ) made of filament borosilicate glass capillaries (WPI, Sarasota, Fla). Signals were amplified with a SEC-10LX amplifier (NPI Electronic, Tamm, Germany) and acquired with Pulse software (HEKA, Lambrecht, Germany). A defined stimulation frequency $(2-15 \mathrm{~Hz})$ was applied using a square pulse stimulator (SD9; Grass Technologies, West Warwick, RI). Data were analyzed with the Mini Analysis program (Synaptosoft, Fort Lee, NJ). Pharmacologic inactivation of gap junctions was performed by titrating defined volumes (2-100 $\mu \mathrm{L})$ of 1-heptanol (Sigma-Aldrich) to the medium.

\section{Statistical Analysis}

Numeric data are expressed as mean \pm 1 standard deviation. Statistical analyses were performed using the Statistical Package for the Social Sciences (release 20; IBM, Somers, NY). Data were tested by 1-way analysis of variance followed by a Bonferroni post hoc test for multiple comparisons.

\section{RESULTS \\ Isolation and Culture of Skeletal Myoblast Cells}

The SMB isolation process yielded $3.80 \pm 1.77 \times 10^{6}$ cells per $100 \mathrm{mg}(\mathrm{n}=5)$ of skeletal muscle tissue from neonatal mice. After 3 preplating steps and a subsequent incubation for 48 hours, the total cell number was reduced to approximately $50 \%$. The majority of the remaining adherent cells showed the typical spindle-shaped morphology of SMBs (Figure 1, A), and immunocytochemical analysis revealed a majority of these cells to be positive for desmin (Figure 1, B). This was confirmed quantitatively by flow 

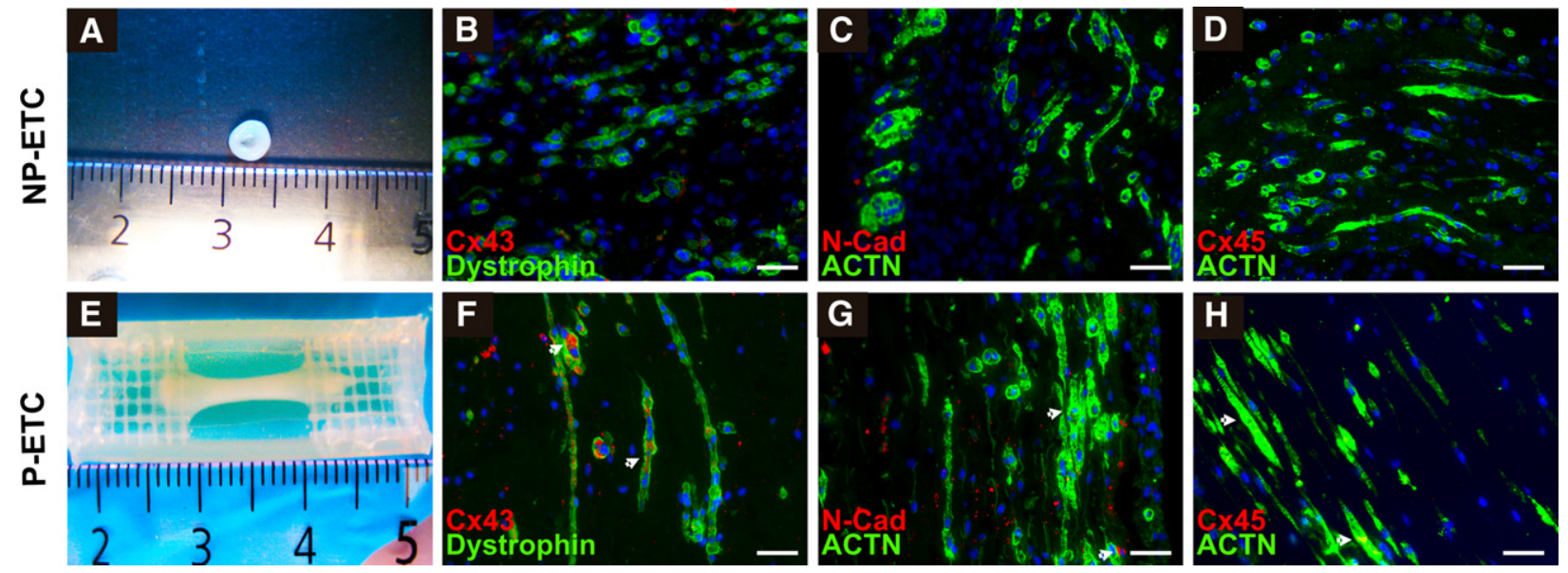

FIGURE 2. Characterization of ETCs. SMBs and myotubes from nonpreconditioned engineered tissue construct (NP-ETC; A-D) and preconditioned engineered tissue construct ( $P$-ETC; E-H) conditions. Macroscopic images of NP-ETC (A) and P-ETC (E). Immunohistochemical staining confirms increased gap junction (arrows, connexin43 [Cx43] and connexin45 [Cx45]) and adhesion protein (N-cadherin [N-Cad]) expression for P-ETC (F-H) compared with NP-ETC (B-D). The regression pattern of myotube-specific (dystrophin) and muscle-specific structural markers $(\alpha$-actinin $[A C T N])$ was similar for both conditions. Scale bars $=50 \mu \mathrm{m}$.

cytometric analysis showing $89.5 \% \pm 4.0 \%(\mathrm{n}=5)$ desmin-positive cells. A further 10 days of cell culture expansion yielded $86.71 \pm 10.66 \times 10^{6}$ cells per $100 \mathrm{mg}$ of tissue with even further increased purity of desminpositive cells $(97.1 \% \pm 0.1 \%, \mathrm{n}=5$; Figure $1, C$ and $D)$. When changing culture conditions to differentiation medium, SMBs changed morphology and fused to multinucleated, spontaneously contracting myotubes, showing expression of sarcomeric $\alpha$-actinin but not retaining expression of gap junction protein $\mathrm{Cx} 43$ (Figure 1, $E$ and $F$ ).

\section{Construct Morphology and Co-Culture}

SMBs from cell culture expansion were used for the fabrication of ETCs. The application of $5 \times 10^{6}$ cells per ETC resulted in a homogeneous and longitudinal alignment of myotubes in P-ETC, whereas NP-ETCs showed no defined orientation of cells (Figure 2, $A, B, E$, and $F$ ). Immunohistochemical analysis revealed ubiquitous expression of dystrophin and sarcomeric $\alpha$-actinin for cells within the ETCs. Expression of gap junction proteins $\mathrm{Cx} 43$ and connexin45, as well as adherens junction protein $\mathrm{N}$-cadherin, was detectable only in P-ETCs and not in NP-ETCs (Figure 2, $B, D, F$, and $H$ ).

\section{Co-Culture and Electrophysiologic Analyses}

For co-cultures, the center sections of ETCs were prepared to obtain the regions of the ETCs with the highest and most reproducible longitudinal alignment of embedded SMBs ${ }^{15}$ and carefully positioned in funnel dishes to guarantee direct contact with the EHSs. For 8 of 10 co-culture experiments, P-ETCs and EHSs remained physically attached for 6 days during co-culture (NP-ETCs: 6/10; K-ETCs: 4/10; Figure E1, $A-G$ ).
Electrophysiologic measurements were performed to investigate electrical coupling between cells in the ETCs and EHSs. Sharp glass electrodes were used to target individual cells in EGFP-positive EHSs for recording of intracellular action potentials (APs) after stimulation in ETCs or EHSs (Figure 3, $A$ and $B$ ).

When the stimulation electrode was placed in the ETCs (S1-R), only the P-ETC group demonstrated APs in unison with EHS cells (Figure E1, $H$ ), as opposed to the NP-ETC and K-ETC groups, in which only APs from spontaneous contractions of the EHSs were observed. In all 3 conditions, stimulation within the EHSs (S2-R) resulted in APs spreading between cells in the EHS, which reflects the viability and excitability of the EHS (Figure 3, C-E).

APs from stimulation at $4 \mathrm{~Hz}$ from P-ETCs showed longer delays to stimulation trigger than APs from stimulation from EHSs (Figure 4, A) and resulted in a significantly lower conduction velocity when normalized to distance between location of stimulation and recording $(0.04 \pm 0.02$ ms vs $0.10 \pm 0.05 \mathrm{~ms}, P=.011 ; \mathrm{n}=5$; Figure $4, B)$.

To further assess the quality of electrical coupling between ETCs and EHSs, increased stimulation frequencies were applied. There were significantly higher maximal stimulation frequencies for stable electrical coupling when stimulation within the EHSs was compared with stimulation from the ETCs (Figure 4, $C-F ; 4.82 \pm 1.42 \mathrm{~Hz}$ vs $10.58 \pm 1.56 \mathrm{~Hz} ; P=.0009 ; \mathrm{n}=5)$. Higher stimulation frequencies led to irregular "skips" in the resulting APs (Figure 4, D).

To verify that the stimulation was propagated through electrical coupling by gap-junctions between cells, and not a conduction artifact caused by a field stimulation effect, the gap-junction inhibitor 1-heptanol was added 


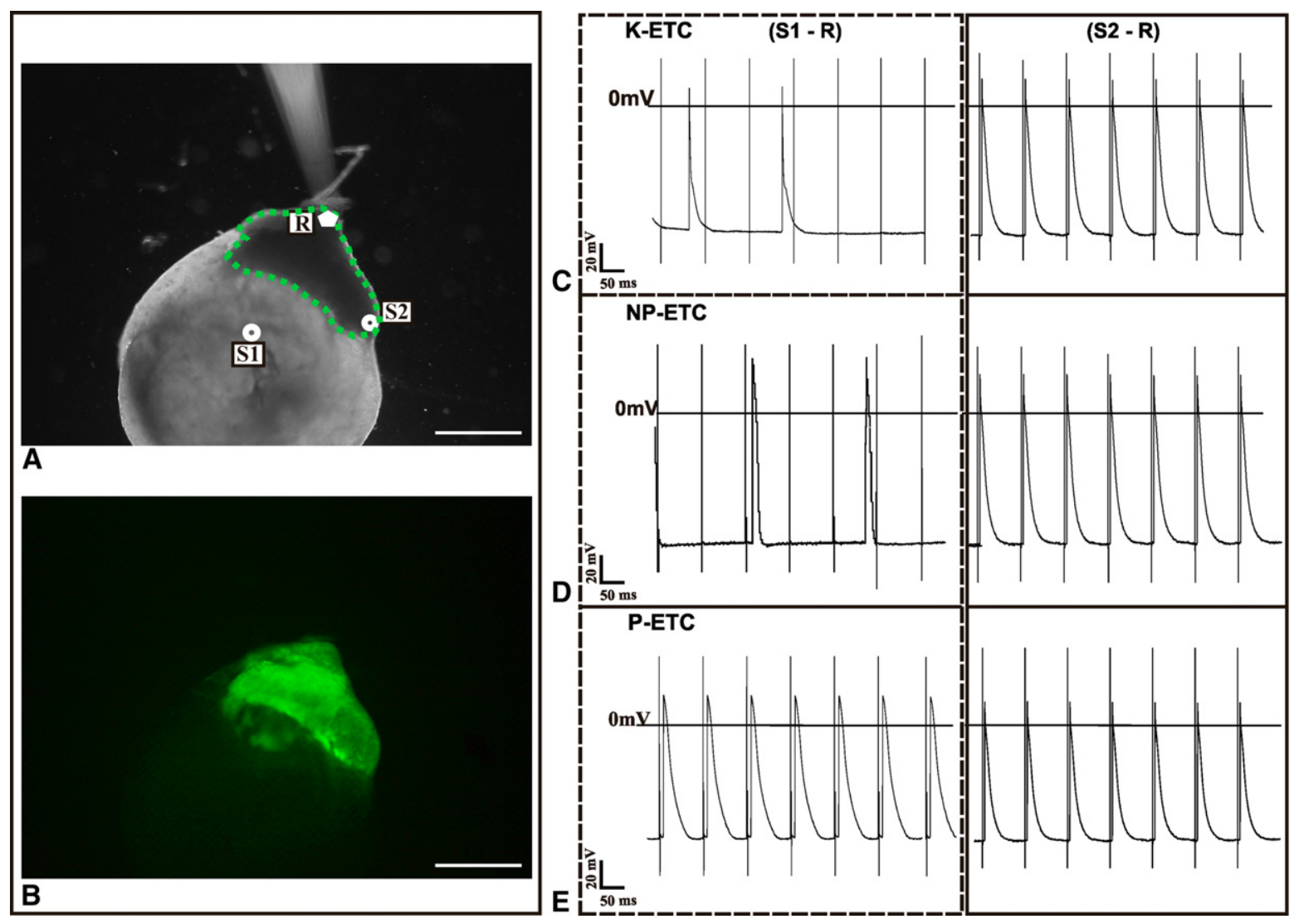

FIGURE 3. Electrophysiologic measurements of EHSs co-cultured with ETCs. A, Positions of electrodes for electrophysiologic measurements: stimulation in the ETC (S1), stimulation in the EHS (S2), and recording in the EHS (R). B, eGFP-positive embryonic ventricle slice (EHS) in co-culture with ETC. C-E, Representative APs measured at R from stimulation at S1 (ETC) and S2 (EHS) for killed engineered tissue construct ( $K$-ETC; C), nonpreconditioned tissue construct (NP-ETC; D), and preconditioned engineered tissue construct ( $P$-ETC; E). Traces on the left show AP at R from stimulation at $\mathrm{S} 1$ (ETC to EHS), and traces on the right show AP at R from stimulation at S2 (EHS to EHS). Scale bars $=1 \mathrm{~mm}$.

incrementally to the media until the stimulation failed to evoke APs.

Although 1-heptanol eventually blocked AP generation in the EHSs independently of whether the stimulation originated in the ETCs or within EHSs, the concentration of inhibitor was significantly lower for ETC-to-EHS conduction block compared with EHC-to-EHS conduction block (Figure $4, G-J ; 0.22 \pm 0.07 \mathrm{mmol} / \mathrm{L}$ vs $0.93 \pm 0.15$ $\mathrm{mmol} / \mathrm{L} ; P=.0004 ; \mathrm{n}=3$ ).

The observed blocking effects were completely reversible under decreasing 1-heptanol concentrations (Figure E1, I).

\section{Histologic Analyses of Co-Cultures}

Histochemistry (Masson's trichrome; Figure 5, C) of the border zone revealed close physical contact of ETCs and EHCs, but a markedly lower cell density in the ETCs compared with the EHSs. Immunohistochemistry demonstrated desmin expression across the border zone, with less expression of this protein in the ETCs compared with the EHSs (Figure 5, D). Cx43 expression was high in the EHSs and in the immediate border zone to the
ETCs with only minimal expression within the ETCs (Figure 5, E).

\section{DISCUSSION}

In the present study, we investigated the physical and electrophysiologic integration of SMB-based ETCs in an in vitro transplantation model. Our major findings can be summarized as follows:

First, we have shown highly efficient isolation of expandable SMB populations from neonatal murine muscle tissue. Cells from these preparations nearly ubiquitously expressed the myogenic marker desmin, emphasizing the absence of contaminating fibroblasts and homogeneity of enriched cells with a functional muscle cell phenotype. Subsequent change of cell culture conditions led to differentiation of single cell SMBs to syncytical, spontaneously contracting myotubes, underlining the efficient generation of cellular structures with the ability to generate contractile force.

Second, ETCs produced with SMBs and matrix components were subjected to unidirectional strain during differentiation of the cells into contractile myotubes. 


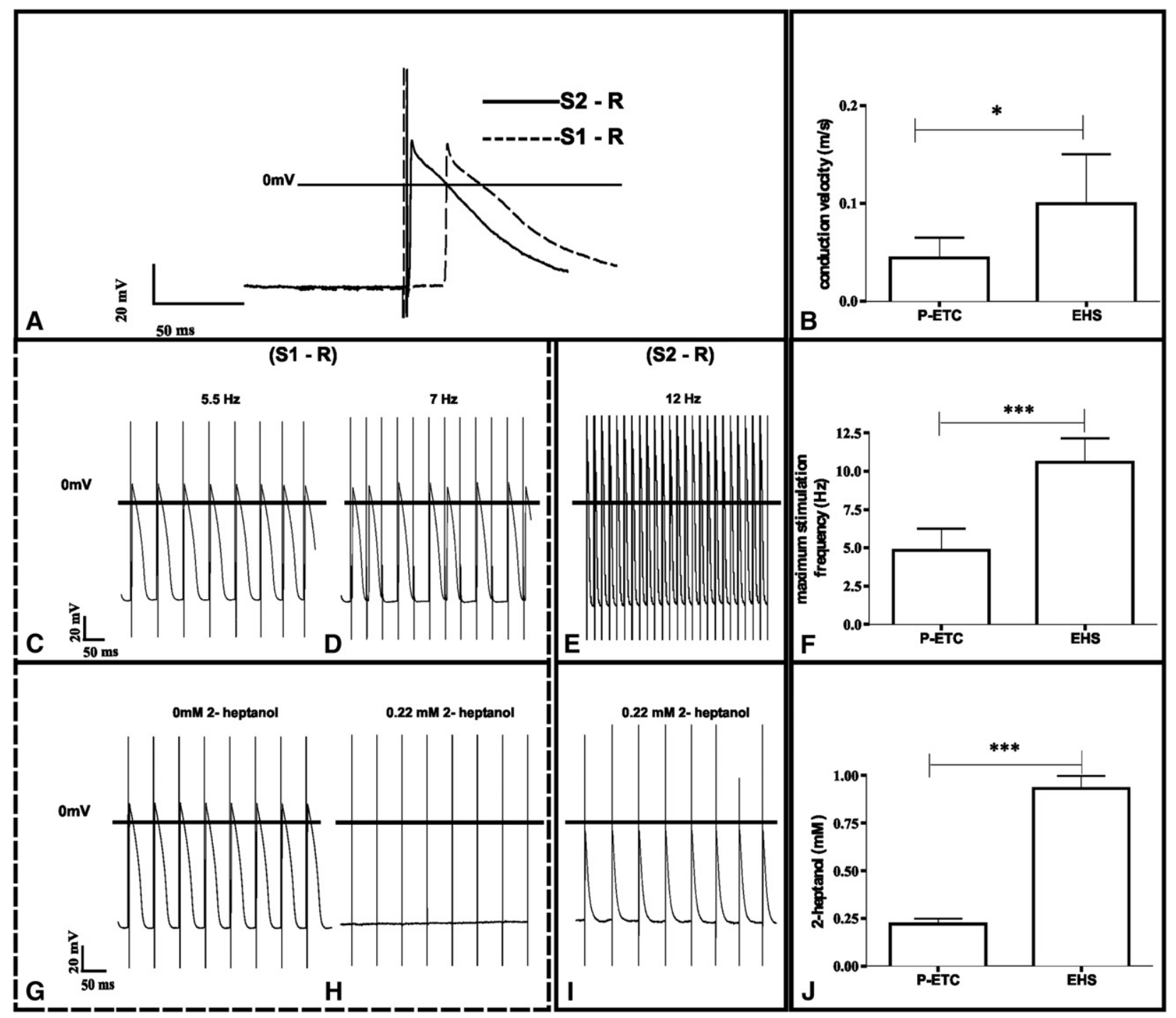

FIGURE 4. Characterization of electrophysiologic coupling between preconditioned engineered tissue constructs $(P-E T C)$ and embryonic heart slice $(E H S)$. A and B, Conduction velocity: overlay of exemplary EHS APs (A) evoked by unipolar stimulation in the ETC (S1) and EHS (S2). Significant differences in conduction velocity measurements (B) between P-ETC to EHS and EHS to EHS. C-F, Maximum stimulation frequency: P-ETC stimulation and EHS measurement show APs at $5.5 \mathrm{~Hz}$ stimulation (C), but resulting in conduction blocks at $7 \mathrm{~Hz}$ (D), whereas EHS stimulation follows EHS recording until $12 \mathrm{~Hz}$ without conduction blocks (E), resulting in different maximum stimulation frequency between P-ETC to EHS and EHS to EHS measurements (F). G-J, 1-Heptanol sensitivity: AP at EHS from $5.5 \mathrm{~Hz}$ stimulation at P-ETC before 1-heptanol treatment (G) and after addition of $0.2 \mathrm{mmol} / \mathrm{L} \mathrm{1-heptanol} \mathrm{(H).}$ Stimulation at EHS still results in AP at EHS at $0.2 \mathrm{mmol} / \mathrm{L}$ 1-heptanol (I) and 1-heptanol blocking concentration (J) between P-ETC to EHS and EHS to EHS measurements. $* P<.05$. $* * * P<.001, \mathrm{n}=5$.

Immunohistochemical analyses revealed continued expression of gap junction and adherens junction proteins, which are necessary for the functional integration of (transplanted) cells in the heart. In ETCs that were not mechanically stimulated (NP-ETCs), these proteins were expressed at low levels and the cells in the constructs remained unorganized.

Third, co-culture of P-ETCs and vital EHSs, which served as an in vitro transplantation model, showed physical engraftment of the engineered tissue with the native tissue and electrophysiologic integration of skeletal muscle-derived cells in ETCs to cardiomyocytes in vital EHSs. By using sharp electrode measurements, we quantitatively determined the efficiency of the coupling between ETCs and EHSs and compared values for conduction velocity, maximum stimulation frequency, and sensitivity to specific pharmacologic gap junction inhibitors to native electrophysiologic coupling within the EHS, serving as an internal positive control. Our results clearly showed electrophysiologic coupling of cells within the ETC to cells within the EHS, but for all 3 parameters examined, this occurred to a lesser extent than the coupling of cells within the native heart tissue. 


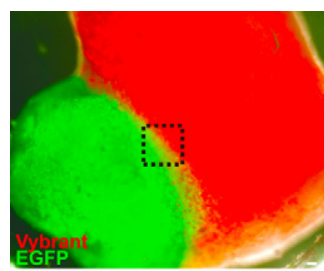

A

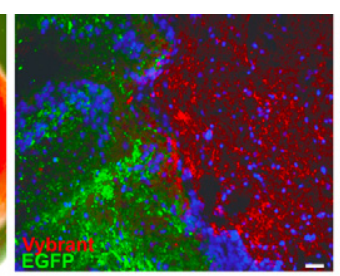

B

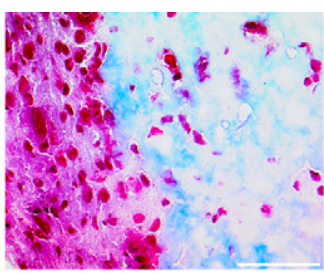

C

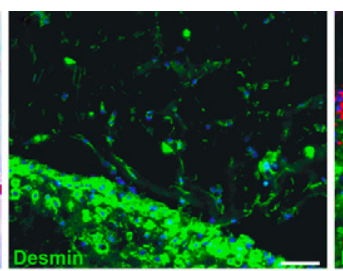

D

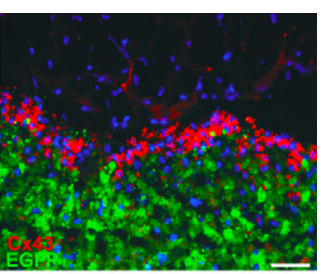

E

FIGURE 5. Histologic analysis of co-cultured engineered heat tissue slices and engineered heart tissue at day 6. A, Macroscopic fluorescence picture of EHS (green: enhanced green fluorescent protein [EGFP]) and P-ETC (red: Vybrant DiI [Invitrogen, Karlsruhe, Germany]). B, Fluorescence micrograph of the P-ETC/EHS border zone. C, Masson's trichrome staining of the P-ETC/EHS border zone (blue: collagen, red: cytoplasm). Immunohistochemical staining for desmin (green) (D) and EGFP (green) and Cx43 (red) (E) in P-ETC/EHS border zone. Cx43 was highly expressed in myotubes in the P-ETC/EHS border zone. Scale bars $=50 \mu \mathrm{m}$.

Isolation of skeletal muscle-derived cell populations has been achieved by various methods, ${ }^{18,19}$ usually including preplating steps during the initial phase of culturing crude primary cell suspensions. This technique serves to separate cell populations on the basis of their attachment to plastic surfaces and is often used for the removal of unwanted fibroblasts, but also for the enrichment of specific multipotent progenitor cell populations. ${ }^{20,21}$ In our case, SMBs were acquired from neonatal tissue for reasons of cell culture compatibility and expansion potential, ${ }^{22}$ and culture conditions were optimized to generate high numbers of functionally competent SMBs for the subsequent fabrication of ETCs.

By applying directional mechanical strain on the tissue constructs, the embedded SMBs were oriented in a longitudinal fashion and condensation of the hydrogel led to a compact and uniform distribution of cells. Furthermore, the expression of gap junction proteins $\mathrm{Cx} 43, \mathrm{Cx} 40$, and N-cadherin was maintained during maturation of SMBs to myotubes. This effect of mechanical signal transduction has been described for the expression of genes involved in various mechanistic pathways, ${ }^{23}$ including the expression of connexins, ${ }^{24,25}$ and is considered to be linked to integrins and cadherins, ${ }^{26,27}$ whereas the exact mechanism is still not fully understood. We showed that electrophysiologic integration to cardiac tissue is only possible when SMBbased ETCs are subjected to tensile strain, demonstrating the necessity for mechanical preconditioning. This characteristic of skeletal muscle-generated progenitor cells has been described ${ }^{28}$ but never as a prerequisite for electrical integration.

Nevertheless, SMBs have been one of the first cell populations that have been applied in clinical trials for cardiac cell therapy, ${ }^{29}$ but they showed poor reproducible therapeutic efficacy in the most recent clinical trials., ${ }^{2,30}$ The induction of ventricular arrhythmias after SMB transplantation has been a recurring and intensely debated issue. A direct association of immature phenotypes of cell transplants and decreased conduction velocity, ${ }^{31}$ as well as improper alignment of gap junction and adherens proteins, was demonstrated in vitro and in animal models. ${ }^{32}$

It is now generally accepted that resolving the challenges regarding electrophysiologic integration remains a major challenge in advancing the clinical utility of cell-based cardiac therapies. ${ }^{33}$

The idea to modify gene expression from SMBs by preconditioning is well established in these approaches. ${ }^{4}$ For example, the transplantation of genetically modified SMBs overexpressing $\mathrm{Cx} 43$ has been shown to prevent postinfarction arrhythmia. ${ }^{11}$ This study demonstrated the potential of tissue engineering and preconditioning of SMBs to build gap junctions and to establish electrical coupling with cardiac cells; however, genetic manipulation limits the potential use of these cells in a clinical setting.

Vital EHSs ${ }^{34,35}$ co-cultured with ETCs allowed us to directly assess the quality of electrical integration using quantitative electrophysiologic parameters. We have shown that SMBs within the ETCs couple electrophysiologically to the EHSs after 6 days of co-culture. However, this coupling was less robust when compared with electrophysiologic connections between cells in the native heart tissue.

Corresponding to our previous findings, ${ }^{14}$ which showed that ETC grafts could augment the cardiac conduction system in a rat model of atrioventricular conduction block, the current study confirms the expression of $\mathrm{Cx} 43$ within the transplanted ETC.

As a structural basis for electrical integration, expression of $\mathrm{Cx} 43$ at the EHS-ETC interface was shown for the mechanically P-ETCs as opposed to the control NP-ETCs, confirming the notion of $\mathrm{Cx} 43$ being essential for cardiac electrophysiologic coupling.

\section{Study Limitations}

Calcium transient imaging experiments were not performed because they were beyond the primary scope of the present study. However, we recognized that the detailed characterization of the calcium transients of the different tissues may help identify the origin of potential ectopic 
arrhythmias. ${ }^{3,6}$ Future experiments will focus on using voltage- or calcium-sensitive dyes to further assess the connectivity of the tissues using optical mapping as described previously. ${ }^{14}$

Furthermore, the investigation of the contractile properties of SMBs embedded in the ETCs and their ability to couple mechanically to the host myocardium are of significant importance. In vitro determination of developed force as fatigue testing would provide further insight. In addition to the in vivo electrical integration of the tissue constructs that we confirmed previously, ${ }^{14}$ the functional in vivo integration of the tissue constructs needs to be investigated and will be the subject of future projects.

\section{CONCLUSIONS}

We demonstrated electrophysiologic coupling of skeletal myoblast-derived cells with cardiomyocytes in the context of engineered tissues. This is a decisive step forward toward the future application of autologous and functionally competent cells as therapeutic agents for cardiac cell therapy.

\section{References}

1. Hagege AA, Carrion C, Menasche P, Vilquin JT, Duboc D, Marolleau JP, et al. Viability and differentiation of autologous skeletal myoblast grafts in ischaemic cardiomyopathy. Lancet. 2003;361:491-2.

2. Menasche P, Alfieri O, Janssens S, McKenna W, Reichenspurner H, Trinquart L, et al. The Myoblast Autologous Grafting in Ischemic Cardiomyopathy (MAGIC) trial: first randomized placebo-controlled study of myoblast transplantation. Circulation. 2008;117:1189-200.

3. Rubart M, Soonpaa MH, Nakajima H, Field LJ. Spontaneous and evoked intracellular calcium transients in donor-derived myocytes following intracardiac myoblast transplantation. J Clin Invest. 2004;114:775-83.

4. Suzuki K, Brand NJ, Allen S, Khan MA, Farrell AO, Murtuza B, et al. Overexpression of connexin 43 in skeletal myoblasts: relevance to cell transplantation to the heart. J Thorac Cardiovasc Surg. 2001;122:759-66.

5. Reinecke H, Minami E, Virag JI, Murry CE. Gene transfer of connexin43 into skeletal muscle. Hum Gene Ther. 2004;15:627-36.

6. Abraham MR, Henrikson CA, Tung L, Chang MG, Aon M, Xue T, et al. Antiarrhythmic engineering of skeletal myoblasts for cardiac transplantation. Circ Res. 2005;97:159-67.

7. Formigli L, Francini F, Tani A, Squecco R, Nosi D, Polidori L, et al. Morphofunctional integration between skeletal myoblasts and adult cardiomyocytes in coculture is favored by direct cell-cell contacts and relaxin treatment. Am J Physiol Cell Physiol. 2005;288:C795-804.

8. Squecco R, Sassoli C, Nuti F, Martinesi M, Chellini F, Nosi D, et al. Sphingosine 1-phosphate induces myoblast differentiation through $\mathrm{Cx} 43$ protein expression: a role for a gap junction-dependent and -independent function. Mol Biol Cell. 2006; 17:4896-910.

9. Siepe M, Giraud MN, Pavlovic M, Receputo C, Beyersdorf F, Menasche P, et al. Myoblast-seeded biodegradable scaffolds to prevent post-myocardial infarction evolution toward heart failure. J Thorac Cardiovasc Surg. 2006;132:124-31.

10. Stagg MA, Coppen SR, Suzuki K, Varela-Carver A, Lee J, Brand NJ, et al. Evaluation of frequency, type, and function of gap junctions between skeletal myoblasts overexpressing connexin43 and cardiomyocytes: relevance to cell transplantation. FASEB J. 2006;20:744-6.

11. Roell W, Lewalter T, Sasse P, Tallini YN, Choi BR, Breitbach M, et al. Engraftment of connexin 43-expressing cells prevents post-infarct arrhythmia. Nature. 2007;450:819-24.

12. Segers VF, Lee RT. Stem-cell therapy for cardiac disease. Nature. 2008;451: 937-42.

13. Neef K, Choi YH, Weichel A, Rahmanian PB, Liakopoulos OJ, Stamm C, et al. The influence of cardiovascular risk factors on bone marrow mesenchymal stromal cell fitness. Cytotherapy. 2012;14:670-8.
14. Choi YH, Stamm C, Hammer PE, Kwaku KF, Marler JJ, Friehs I, et al. Cardiac conduction through engineered tissue. Am J Pathol. 2006;169:72-85.

15. Perumal Srinivasan S, Neef K, Treskes P, Liakopoulos OJ, Stamm C, Cowan DB, et al. Enhanced gap junction expression in myoblast-containing engineered tissue. Biochem Biophys Res Commun. 2012;422:462-8.

16. Hannes T, Halbach M, Nazzal R, Frenzel L, Saric T, Khalil M, et al. Biological pacemakers: characterization in an in vitro coculture model. J Electrocardiol. 2008;41:562-6.

17. Pillekamp F, Reppel M, Dinkelacker V, Duan Y, Jazmati N, Bloch W, et al. Establishment and characterization of a mouse embryonic heart slice preparation. Cell Physiol Biochem. 2005;16:127-32.

18. Rando TA, Blau HM. Primary mouse myoblast purification, characterization, and transplantation for cell-mediated gene therapy. J Cell Biol. 1994;125: 1275-87.

19. Musaro A, Barberi L. Isolation and culture of mouse satellite cells. Methods Mol Biol. 2010;633:101-11.

20. Arsic N, Mamaeva D, Lamb NJ, Fernandez A. Muscle-derived stem cells isolated as non-adherent population give rise to cardiac, skeletal muscle and neural lineages. Exp Cell Res. 2008;314:1266-80.

21. Gharaibeh B, Lu A, Tebbets J, Zheng B, Feduska J, Crisan M, et al. Isolation of a slowly adhering cell fraction containing stem cells from murine skeletal muscle by the preplate technique. Nat Protoc. 2008;3:1501-9.

22. Danoviz ME, Yablonka-Reuveni Z. Skeletal muscle satellite cells: background and methods for isolation and analysis in a primary culture system. Methods Mol Biol. 2012;798:21-52.

23. Wang N, Tytell JD, Ingber DE. Mechanotransduction at a distance: mechanically coupling the extracellular matrix with the nucleus. Nat Rev Mol Cell Biol. 2009; 10:75-82.

24. Wang TL, Tseng YZ, Chang H. Regulation of connexin 43 gene expression by cyclical mechanical stretch in neonatal rat cardiomyocytes. Biochem Biophys Res Commun. 2000;267:551-7.

25. Lee SW, Kang HJ, Lee JY, Youn SW, Won JY, Kim JH, et al. Oscillating pressure treatment upregulates connexin43 expression in skeletal myoblasts and enhances therapeutic efficacy for myocardial infarction. Cell Transplant. 2009;18:1123-35.

26. Gomez GA, McLachlan RW, Yap AS. Productive tension: force-sensing and homeostasis of cell-cell junctions. Trends Cell Biol. 2011;21:499-505.

27. Leckband DE, le Duc Q, Wang N, de Rooij J. Mechanotransduction at cadherinmediated adhesions. Curr Opin Cell Biol. 2011;23:523-30.

28. Iijima Y, Nagai T, Mizukami M, Matsuura K, Ogura T, Wada H, et al. Beating is necessary for transdifferentiation of skeletal muscle-derived cells into cardiomyocytes. FASEB J. 2003;17:1361-3.

29. Taylor DA, Atkins BZ, Hungspreugs P, Jones TR, Reedy MC, Hutcheson KA et al. Regenerating functional myocardium: improved performance after skeletal myoblast transplantation. Nat Med. 1998;4:929-33.

30. Tongers J, Losordo DW, Landmesser U. Stem and progenitor cell-based therapy in ischaemic heart disease: promise, uncertainties, and challenges. Eur Heart J. 2011;32:1197-206

31. Kehat I, Gepstein A, Spira A, Itskovitz-Eldor J, Gepstein L. High-resolution electrophysiological assessment of human embryonic stem cell-derived cardiomyocytes: a novel in vitro model for the study of conduction. Circ Res. 2002;91: 659-61.

32. Kehat I, Khimovich L, Caspi O, Gepstein A, Shofti R, Arbel G, et al. Electromechanical integration of cardiomyocytes derived from human embryonic stem cells. Nat Biotechnol. 2004;22:1282-9.

33. Chen HS, Kim C, Mercola M. Electrophysiological challenges of cell-based myocardial repair. Circulation. 2009;120:2496-508.

34. Halbach M, Pillekamp F, Brockmeier K, Hescheler J, Muller-Ehmsen J, Reppel M. Ventricular slices of adult mouse hearts-a new multicellular in vitro model for electrophysiological studies. Cell Physiol Biochem. 2006;18:1-8.

35. Pillekamp F, Halbach M, Reppel M, Pfannkuche K, Nazzal R, Nguemo F, et al Physiological differences between transplanted and host tissue cause functional decoupling after in vitro transplantation of human embryonic stem cell-derived cardiomyocytes. Cell Physiol Biochem. 2009;23:65-74.

\section{Discussion}

Dr Y. Joseph Woo (Philadelphia, Pa). Dr Choi, I congratulate you and your colleagues on an outstanding body of work. Your work is very innovative. The mechanical preconditioning, your in vitro transplant model of heart slices, sophisticated 
electrophysiologic studies, proper biologic controls, and loss of function and restoration of function controls all should be commended. I have 2 quick questions.

Have you looked at any complementary studies of gap junction function and electrophysiologic coupling, such as direct imaging of calcium transients?

Dr Choi. We did not do that. We performed a dye transfer experiment by immersing one end into calcium AM, the dye was transferred, and the dye transfer could be stopped by additional administration of 1-heptanol.

Dr Woo. Would you comment on any ongoing in vivo studies or speculate on your work transitioning into an in vivo model? Would multiple factors, such as the varied vectors of natural cardiac contractility, potentially decondition your preconditioned myotubules and might your engineered construct serve as a focus for a reentrant tachycardia?

Dr Choi. We also performed transplantation in vivo in mice, and by small animal magnetic resonance imaging in these mice, we observed that the size of the scar decreased and the contractility of the left ventricle increased.

In regard to the other question, we are starting a clinical trial. We are trying to translate everything to meet the Good Manufacturing Practice guidelines, and we are just waiting for approval. 


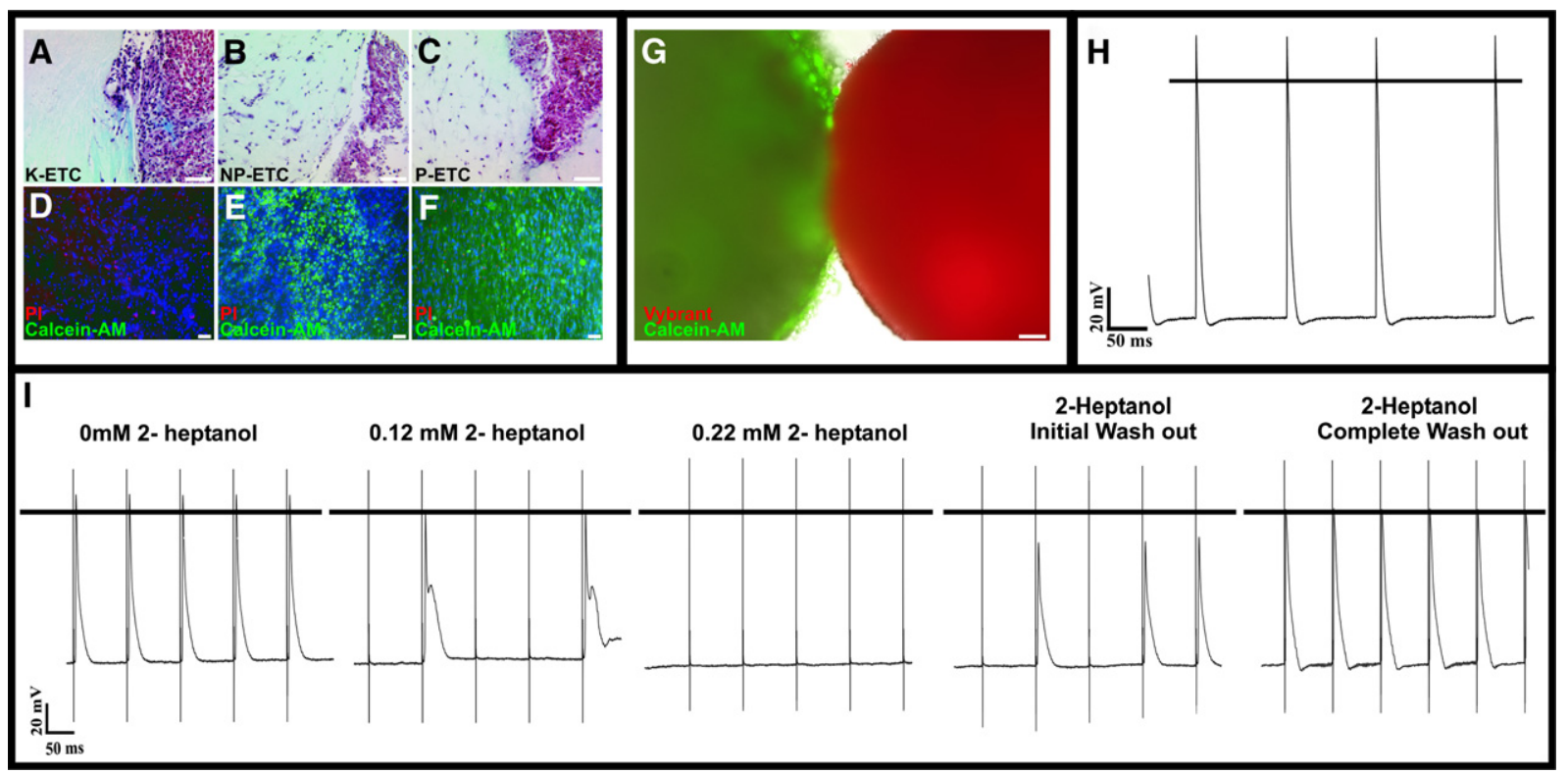

FIGURE E1. Masson's trichrome staining of the co-culture samples at the junction of (A) killed engineered tissue construct $(K$-ETC)/EHS and (B) nonpreconditioned engineered tissue construct (NP-ETC)/EHS shows poor grafting, whereas (C) preconditioned engineered tissue construct ( $P$-ETC)/ EHS shows close contact of adjacent tissues. D-F, Staining of ETCs shows a majority of dead (propidium iodide positive) cells for K-ETC (D), whereas NP-ETC (E) and P-ETC (F) show mainly vital (calcein AM positive) cells. G, Macroscopic fluorescence picture of Vybrant Dil (red) labeled EHS coculture with calcein AM (green) labeled EHS to show poor attachment of adjacent tissues. H, Spontaneous AP of EHS. I, APs of P-ETC/EHS coculture during 2-heptanol treatment and after washout. Scale bars $=50 \mu \mathrm{m}$. 